\title{
VOLUNTARY CONVERGENCE
}

BY

W. R. MATHEWSON

EDINBURGH

THE importance of training voluntary convergence, emphasized in the Middlemore lecture, which may be read in the Brit. Jl. of Ophthal. of September, 1941, is confirmed by some observations. made independently.

In 1928 I was working abroad in a locality where :

(1) There was isolation from other ophthalmic surgeons, so that observations are proportionately free from the influence of other ophthalmic opinion.

(2) There was present a large number of men; typically army officers who, having spent the earlier part of their careers in regimental work, where they were accustomed to watch the sky-line of the hills or to detect movements in the far away of the desert, were at the age of 45 to .55 confined to arduous office work requiring a corresponding degree of convergence, a function previously comparatively little used by them.

(3) Observations, commencing in 1929, before the publication of Stutterheim's Monograph in 1931,- have the value of, at that date, not being undër its influence.

The complaints were, general eyestrain, not relieved by spectacles.

The exercises used consisted of :

(1). Placing increasingly strong prisms in the trial frame in series, the patient looking at a light 6 metres away.

(2) With prisms in the trial frame the light was brought from 6 metres to about 1 metre, and then slowly away again to 6 metres, a wearisome business for the doctor if continued long, and which; by a sudden inspiration one day, I varied by making the patient do the walking, a procedure $I$ found enhanced attention, and expedited desire for cure, especially in the hot weather.

(3) Prisms were placed in the frame, bases out in convergence deficiency, and the frame raised and lowered, the patient being instructed to make the two lights seen at the other end of the room into a single image. When the frame was raised he.would see the light double for a moment, and then it would become single, and when the frame was lowered, he had by a voluntary effort of convergence to strive to fuse the two images to make one. This would be done about ten times and then 
the strength of the prisms increased, and the frames again raised and lowered ten times, and so on.

(4) Prisms were also given to wear at home for some days, for convergence deficiencies base out, thus continuing the exercises, and forcing the eyes to converge.

The conclusion was formed that in the exercises of raising and lowering the prisms, there was a definite voluntary effort on the part of the patient, and that, unless this exercise of raising and lowering the prisms was used, the cure was not so successful or permanent.

In other words Williamson Noble's view of the great importance of voluntary convergence is corroborated by a set of observations quite isolated, and commencing before Stutterheim's Monograph was published, and, therefore to that extent uninfluenced by it.

Later, after his monograph was published, I tried simply increasing the prisms base out by series, having the prisms mounted as a battery, but I again found that unless I also used " Jump Convergence," that is a voluntary convergence, obtained by raising and lowering the prisms the cure was not nearly so satisfactory or permanent, again confirming Williamson Noble's remarks about being under the influence of Stutterheim's Monograph in the early series, and not then using Jump Convergence ór getting such good results as when voluntary convergence was taught.

There was, of course, nothing very novel about these exercises, they were all in the books and the avoidance of mechanical contrivances such as synoptophores or their prototypes, etc., was no virtue but necessity, because they were not available owing to geographical isolation.

\section{Summary}

Observations commencing in 1929 confirmed independently the importance of training voluntary convergence as emphasized in the Middlemore Lecture.

Originally I was teaching voluntary convergence but when, like Williamson Noble, I came under the influence of Stutterheim, and 'used his methods' only, my results were not so good, and I therefore returned to teaching voluntary convergence, and got improved results. 